\title{
Processing of a Novel Zn Alloy Micro-tube for Biodegradable
}

\section{Vascular Stent Application}

\author{
Chang Wang ${ }^{1}$, Zhentao $\mathrm{Yu}^{1 *}$, Yajun Cui ${ }^{1,2}$, Yafeng Zhang ${ }^{1}$, Sen Yu ${ }^{1}$, Gongqi Qu ${ }^{3}$, Haibo Gong ${ }^{3}$ \\ ${ }^{1}$ Northwest Institute for Nonferrous Metal Research, Xi' an 710016, China \\ ${ }^{2}$ Xi' an University of Architecture and Technology, Xi' an 710055, China \\ ${ }^{3}$ Xi' an Advanced Medical Technology Co., Ltd., Xi' an 710077, China
}

[Manuscript received 29 September 2015, received in revised form 12 November, 2015, accepted 12 December 2015]

* Corresponding author. Prof., Ph.D.; Tel./Fax: +86 298626 4213; E-mail address: yzt@c-nin.com (Zhentao Yu).

In recent years, zinc based alloys as a new biodegradable metal material aroused intensive interests. However, the processing of $\mathrm{Zn}$ alloys micro-tubes (named slender-diameter and thin-walled tubes) is very difficult due to their HCP crystal structure and unfavorable mechanical properties. This study aimed to develop a novel technique to produce micro-tube of $\mathrm{Zn}$ alloy with good performance for biodegradable vascular stent application. In the present work, a processing method combined drilling, cold rolling and optimized drawing was proposed to produce the novel $\mathrm{Zn}-0.05 \mathrm{Mg}-0.01 \mathrm{Fe}$ (wt\%) alloy micro-tubes. The micro-tube with outer diameter of $2.5 \mathrm{~mm}$ and thickness of $130 \mu \mathrm{m}$ was fabricated by this method and their dimension errors are within $10 \mu \mathrm{m}$. The micro-tube exhibits a fine and homogeneous microstructure, and the ultimate tensile strength and ductility are more than $220 \mathrm{MPa}$ and $20 \%$ respectively. In addition, the micro-tube and stents of $\mathrm{Zn}$ alloy exhibit superior vitro corrosion and expansion performance. It could be concluded that the novel $\mathrm{Zn}$ alloy micro-tube fabricated by above method might be a promising candidate material of biodegradable stent.

Key words: Zn alloy; Micro-tube; Biodegradable stent; Mechanical properties; Dimensional accuracy; Vitro corrosion performance

\section{Introduction}

Bare metal stents are widely used in the treatment of arterial diseases to open stenosed blood vessels physically. However, these stents are proved to cause the long-term risks of in-stent restenosis and thrombosis ${ }^{[1,2]}$. A biodegradable stent, which can opens the stenosed blood vessel until the vessel remodeling and completely degraded and disappear thereafter, is expected as a less-invasive stent to mitigate the long-term side effects ${ }^{[3]}$. In the last decade, some researchers have focused on iron $^{[4-6]}$, magnesium ${ }^{[7-9]}$ and their alloys on biodegradable stent materials. However, the tissue compatibility ${ }^{[10]}$ of pure iron and fast degradation of magnesium and its typical alloys are difficult to meet the clinical application ${ }^{[11]}$. Thus, Zinc alloys with high corrosion resistance have become a new biodegradable stent material in recent years. Zinc is widely acknowledged as an essential element for biological function ${ }^{[12,13]}$. Moreover, the recommended daily value of zinc ranges from $10 \mathrm{mg} \mathrm{day}^{-1}$ for adult males to 2 $\mathrm{mg} \mathrm{day}^{-1}$ for infants ${ }^{[14]}$. The study of D. Vojte $\mathrm{ch}^{[15]}$ shows that the zinc doses of $\mathrm{Zn}$ alloy degradation are negligible compared with the tolerable biological daily limit.

However, compared with the large literature on the corrosion performance of $\mathrm{Zn}$ alloy $^{[16-18]}$, few investigations has been done on the processing of $\mathrm{Zn}$ alloy micro-tubes used 
for biodegradable stents. It is mainly because $\mathrm{Zn}$ alloys are difficult to be directly produced into the required micro-tubes due to the low deformability and unfavorable mechanical properties caused by hexagonal close packed (HCP) crystal structure. The mechanical properties of micro-tubes will be size-dependent within the size range of stent struts ${ }^{[19,20]}$. Generally, micro-tubes required for application are limited the outer diameter no more than 3.0 $\mathrm{mm}$ and thickness of 100-150 $\mu \mathrm{m}$. In addition, the properties (mechanical properties, corrosion performance) and dimensional accuracy of the micro-tube, directly affect the quality and performance of the stent ${ }^{[21]}$. Therefore, it is necessary and significant to have a deeply study on the mechanical properties, dimensional accuracy and corrosion performance of the $\mathrm{Zn}$ alloy micro-tube utilized for biodegradable vascular stents.

In this paper, a novel $\mathrm{Zn}-0.05 \mathrm{Mg}-0.01 \mathrm{Fe}$ (wt $\%$ ) alloy without toxic element for human body ${ }^{[22]}$ was selected to produce micro-tube with good performance for biodegradable vascular stent application. We produced the high-quality micro-tubes through a combination of drilling, cold rolling and drawing. Compared with different drawing method at various drawing conditions and their related mechanical properties, we proposed a novel drawing method by means of wire mandrel to enable high-accuracy cold drawing of the $\mathrm{Zn}$ alloys micro-tubes. This processing method overcame the shortcoming of the poor workability of $\mathrm{Zn}$ alloys and could be used to produce sufficiently long micro-tubes with $2.5 \mathrm{~mm}$ outer diameter. Moreover, the microstructure variation of $\mathrm{Zn}$ alloy tubes during the combined processing method was observed. In addition, the corrosion rates of $\mathrm{Zn}$ alloy micro-tubes immersed in SBF solution were estimated using the weight loss method. Finally, the expansion test of $\mathrm{Zn}$ alloy stents was implemented as a supplementary evaluation for mechanical properties of the drawn micro-tube.

\section{Material and Experimental Procedure}

\subsection{Processing of micro-tubes}

The wrought zinc alloy with composition of $\mathrm{Zn}-0.05 \mathrm{Mg}-0.01 \mathrm{Fe}$ (wt\%) was cast and extruded by Xi' an Advanced Medical Technology, Co., Ltd.. The extruded bars were drilled to tube blanks ( $\$ 12 \mathrm{~mm} \times 2.5 \mathrm{~mm}$ ) and then rolled with an area reduction of less than $20 \%$ every pass when the dimension of tubes reached the outer diameter of $3.0 \mathrm{~mm}$ and thickness of 130-200 $\mu \mathrm{m}$. Hollow sinking (HS) and mandrel drawing (MD) were then carried out with different reduction per pass (R/P), drawing pass (DP) and lubricants. Typical different drawing conditions of rolled $\mathrm{Zn}$ alloy micro-tubes are listed in Table 1. The schematic diagrams of HS and MD are shown in Fig. 1. In the process of HS, the rolled tube is drawn through the drawing die, while the tube is drawn through the gap between the die and the mandrel for MD process. During each pass for rolling and drawing, the tubes were annealed at $300{ }^{\circ} \mathrm{C}$ for $0.5 \mathrm{~h}$ to remove the work-hardening introduced by cold deformation. Finally, the micro-tubes with outer diameter of $2.5 \mathrm{~mm}$ and thickness of $130 \mu \mathrm{m}$ were produced.

\subsection{Mechanical property test}

The tensile mechanical property test was carried out on a universal material test machine (INSTRON5982) with a displacement rate of $1.5 \mathrm{~mm} / \mathrm{min}$ at room temperature. For each group of tests, three micro-tubes were selected according to ASTM E8M-13a standard. Micro-tubes were inserted with copper plugs at their two ends to ensure the test machine jaws to grip the specimens properly.

\subsection{Microstructure analysis}

The specimens of $\mathrm{Zn}$ alloy tubes for microstructure observation were cut from the transverse and longitudinal sections. The specimens were cold-mounted into the epoxy resin, ground with \#180, \#600 and \#1000 grit SiC papers and polished with $1 \mu \mathrm{m}$ diamond pastes, 
then chemically etched by the solution of $20 \mathrm{~g}$ chromic oxide, $100 \mathrm{ml}$ distilled water. The optical microscope (OM, Axio vert A1) was used to observe the grain microstructures of the samples, and the dimension was measured using a three coordinate measuring machine (O-scope-A3020).

\subsection{In vitro corrosion test}

In vitro corrosion tests were performed as follows: The samples were cut from a drawn AZ31 alloy micro-tube, the rolled and drawn micro-tubes of $\mathrm{Zn}$ alloy then cleaned with ethanol. A simulated body fluid (SBF) was prepared ${ }^{[23]}$ and used as the immersion solution. Samples of each group were immersed in $1 \mathrm{~L}$ of the SBF for 48 days at $37{ }^{\circ} \mathrm{C}$. The weight values of samples were measured after cleaned corrosion products at $96 \mathrm{~h}$ intervals during the testing period. Weight loss percentage $(U)$ was calculated as following: $U=\left(W_{0}-W_{n}\right) / W_{0} \times 100 \%$

where $W_{0}$ is the initial weight of sample and $W_{n}$ is the weight after every immersion of $96 \mathrm{~h}$. The corrosion rate was estimated using the weight loss method according to ASTM-G31-72 after the corrosion products were removed in a chromic acid solution, ultrasonically cleaned in absolute ethanol and dried in the open air. The surface morphology was investigated via stereomicroscope (ZEISS STEM 2000 C) and image analysis technique.

\subsection{Balloon expansion test}

The drawn micro-tubes were fabricated into vascular stents through laser etching and electrochemical polishing process. Their expansion abilities were evaluated with a balloon catheter. The vascular stents were crimped onto a balloon at the catheter tip, and then expanded by inflating the balloon with water at $1.0 \mathrm{MPa}$. The structure of the stents was observed by stereomicroscope.

\section{Results and Discussion}

\subsection{Processing optimization of Zn alloy micro-tube}

The mechanical properties of $\mathrm{Zn}-0.05 \mathrm{Mg}-0.01 \mathrm{Fe}$ (wt\%) alloy micro-tubes at various drawing conditions according to Table 1 are shown in Table 2. It exhibits that a good surface quality of the micro-tubes without surface flaw was achieved when the drawing R/P is lower than $15 \%$. It is also observed that the DP should be limited to 5 times and R/P is about $4 \%$ for HS process (see No.3-No.5), and the excessive DP is bad to the plasticity of the micro-tubes ${ }^{[24,25]}$. Oil lubricant is preferred to acquire better mechanical properties of $\mathrm{Zn}$ alloy micro-tubes, compared with No.4 and No.6. It is mainly because relatively dilute lubricant have smaller viscosity, giving smaller friction stress and produce less defects with good surface finish $^{[26]}$. For MD method, the wall of the tube bear a supporting force and compressive stress from the mandrel and die so the precise thickness is obtained, the elongation is also improved.

The processing products from the hollow billets to micro-tubes are shown in Fig. 2(a). As can be seen, rolled and drawn micro-tubes display bright white metallic luster and very smooth surface appearance without any shear cracking or tearing. It can be observed that, the micro-tubes before and after drawn have high roundness without deformation or decentering (Fig. 2(b)-(e)). It indicates that the mandrel drawing method proposed in the present study is very effective to produce $\mathrm{Zn}$ alloy micro-tubes. As shown in Fig. 3, the wall thicknesses of drawn micro-tubes are not exactly uniform while the dimensional accuracy of the outer diameter and inner diameter is extremely high. The maximum variation in wall thickness is nearly $5 \mu \mathrm{m}$, which is about $3.8 \%$ of the wall thickness. The following three factors might cause the variations in wall thickness. Firstly, tube blanks from drilling had non-uniform wall thicknesses due to the swing bring from spin. The initial non-uniformity of wall thickness 
could be partially revised by subsequent cold rolling and drawing, but it could not be eliminated completely. Secondly, the dimensional precisions of the rolls, mandrel and drawing dies, depending on the machining precisions, affect the dimensional accuracy of the tubes. Thirdly, during rolling and drawing at room temperature, the tube underwent both elastic and plastic deformation, and springback after deformation would be inevitable ${ }^{[27]}$. Thus, ultra close tolerances of the tooling must be guaranteed for the prerequisites for preparing high-precision micro-tubes.

As mentioned above, the micro-tube fabricated with the processing procedure of No.7 exhibited superior mechanical properties, high-quality surface and excellent dimensional accuracy. In order to evaluate the possible application of such micro-tubes for vascular stent, the vitro corrosion performance and expandability of the micro-tubes were examined in the following sections.

\subsection{Properties evaluation of Zn alloy micro-tube}

\subsubsection{Microstructure of $\mathrm{Zn}$ alloy micro-tube}

As we all know, fine and homogeneous microstructure gives rise to superior properties, so controlling the microstructure of the $\mathrm{Zn}$ alloy after cold forming and subsequent annealing is very important to meet the requirements of biodegradable stents. Fig. 4 shows the microstructure of the $\mathrm{Zn}$ alloy tubes, (a), (c), (e), (g) are cross section and (b), (d), (f), (h) are longitudinal section. All the $\mathrm{Zn}$ alloy tubes exhibit a fine and homogeneous microstructure. The rolled micro-tube shows an incomplete recrystallized microstructure with a mean grain size of approximately $6 \mu \mathrm{m}$ (Fig. 4(c) and 4(d)) in contrast with the microstructure of drilled tube (Fig. 4(a) and 4(b)). After cold drawing (Fig. 4(e) and 4(f)), twins appeared in the coarse grains due to the poor plasticity of $\mathrm{Zn}$ alloy which is the same as other HCP-structured materials ${ }^{[28]}$, in which twinning is a common deformation mode due to insufficient slip systems ${ }^{[29]}$. The magnesium alloy tubes can also induce deformation twins when deforming from $3 \%$ to $15 \%{ }^{[30,31]}$. Therefore, a large amount of twinning was detected in the drawn zinc alloy micro-tubes. The recrystallized grain microstructure was obtained by subsequent annealing treatment (Fig. 4(g) and 4(h)). The deformed microstructure, including twins and deformed grains, disappeared and the homogeneous recrystallized grains were increased to about $20 \mu \mathrm{m}$.

\subsubsection{Vitro corrosion performance of $\mathrm{Zn}$ alloy micro-tube}

Fig. 5(a) shows the surface morphology of the rolled $\mathrm{Zn}$ alloy micro-tube sample after 48 days of immersion in SBF. Almost no corrosion mark was observed on the surface of the whole $\mathrm{Zn}$ alloy micro-tube (Fig. 5(a)). The drawn $\mathrm{Zn}$ alloy micro-tube exhibited little flat corrosion marks in the whole (Fig. 5(b)). However, the AZ31 ally micro-tubes were completely degradation into graininess in the same corrosion condition after $96 \mathrm{~h}$, as show in Fig. 5(c) (looking down to the beaker bottom), which is equal to the corrosion rate of $16.40 \mathrm{~mm} / \mathrm{year}^{[32]}$. Fig. 6 illustrates the weight loss percentage $(U)$ of $\mathrm{Zn}$ alloy micro-tubes samples during immersion test. It can be seen that the $U$ values of both rolled and drawn micro-tubes indicate a rapid increase during the early days then become stabilized in the later days. The reduced of the increase speed of $U$ value is mainly because formation of $\mathrm{Zn}(\mathrm{OH})_{2}$ and precipitation of corrosion products on the samples' surfaces separate the solution and exposed samples' surface during immersion test ${ }^{[33]}$. Nevertheless, the $U$ value of drawn micro-tubes is clearly higher than rolled micro-tubes from beginning to end. It is mainly because more micro-defects were introduced to the drawn micro-tubes because of the existence of tension stress. However, the linear weight loss percentage with time and the relative flat surface morphology indicated that the sample of $\mathrm{Zn}$ alloy micro-tubes exhibited nearly uniform corrosion during immersion.

The $\mathrm{Zn}$ alloy micro-tubes with homogeneous and fine microstructure wrought by adequate 
deformation, thereby the micro-tubes with high quality possess a comparable uniform corrosion $^{[34]}$, in which there is an excellent corrosion resistant with average corrosion rate about $0.040 \mathrm{~mm} /$ year for rolled micro-tubes and $0.062 \mathrm{~mm} /$ year for drawn micro-tubes. While the corrosion rate of WE43 magnesium alloy micro-tube is $0.85 \mathrm{~mm} / \mathrm{year}^{[32]}$. Obviously, the $\mathrm{Zn}$ alloy micro-tubes have a superior corrosion performance compared with the conventional magnesium alloys applied in biodegradable vascular stent.

\subsubsection{Expandability of Zn alloy vascular stent}

The vascular stent was processed from the drawn $\mathrm{Zn}$ alloy micro-tube in $2.5 \mathrm{~mm}$ outer diameter through laser etching and electrochemical polishing processes which is shown in Fig. 7(a). No obvious micro-cracking or other defects in the $\mathrm{Zn}$ alloy stent were observed. Fig. 7(b) and Fig. 7(c) respectively shows the macrographs of the $\mathrm{Zn}$ alloy stent first crimped into 1.3 $\mathrm{mm}$ and then expanded into $3.5 \mathrm{~mm}$. It can be observed that, the stent still keep its structural integrity without any breaking or cracking at the strut connections after uniform expansion. Therefore, it is reasonably convinced that the drawn $\mathrm{Zn}$ alloy micro-tubes have proper mechanical properties to be processed to be vascular stents.

According to above results, the $\mathrm{Zn}$ alloy micro-tubes were successfully fabricated by the combined processing method with high dimensional accuracy without deformation or decentering in diameters and thickness. Moreover, the slender-diameter, thin-walled tubes possess adequate strength and high ductility (UTS $>220 \mathrm{MPa}$ and Elongation $>20 \%$ ) with a fine and homogeneous microstructure. In addition, the $\mathrm{Zn}$ alloy micro-tubes exhibit much smaller corrosion rate and more uniform corrosion than conventional magnesium alloys in SBF. What's more, the vascular stents etching from Zn alloy micro-tube exhibit no obvious breaking or cracking and perform uniform expansion. Hence, it can be safely concluded that the $\mathrm{Zn}$ alloy micro-tubes have a great potential applied in vascular stent by the novel process.

\section{Conclusion}

The processing of micro-tube determining its dimensional accuracy and microstructure as well as mechanical properties, then directly affect the quality and performance of stent devices. In this work, the $\mathrm{Zn}-0.05 \mathrm{Mg}-0.01 \mathrm{Fe}(\mathrm{wt} \%$ ) alloy micro-tubes with outer diameter of $2.5 \mathrm{~mm}$ and thickness of $130 \mu \mathrm{m}$ were successfully fabricated through the drilling, rolling, optimized mandrel drawing and intermediate annealing method. An optimized processing for drawn was as follows: mandrel drawing, reduction per pass (R/P) less than 15\%, 2 times of drawing pass (DP) and oil lubricate. The micro-tubes exhibited high dimensional accuracy with the dimension errors lower than $10 \mu \mathrm{m}$, fine grains microstructure and superior mechanical properties with the ultimate tensile strength larger than $220 \mathrm{MPa}$ and elongation higher than $20 \%$. Moreover, the drawn $\mathrm{Zn}$ alloy micro-tubes showed a nearly uniform corrosion with a low corrosion rate of about $0.062 \mathrm{~mm} / \mathrm{y}$. The stents produced by the $\mathrm{Zn}$ alloy micro-tubes exhibited no micro-cracking before and after expand. Such superior properties indicated that the Zn alloy micro-tube produced using the method described in this study is promising candidate for biodegradable vascular stent application.

\section{Acknowledgments}

This work was supported by the National Basic Research Program of China (973 Program) (Grant No. 2012CB619102), the National Science Foundation of China (Grant No. 31400821) and the innovation fund of Western Metal Materials (Grant No. XBCL-3-14). 
[1] A.J. Nordmann, M Briel, H.C. Bucher, Eur. Heart J. 27 (2006) 2784-2814.

[2] H. Ota, M. Mahmoudi, R. Torguson, L.F. Satler, W.O. Suddath, A.D. Pichard, R. Waksman, Cardiovasc. Revasc. Med. 16 (2015) 151-155.

[3] H. Hermawan, D. Dubé, D. Mantovani, Acta. Biomater. 6 (2010) 1693-1697.

[4] H. Hermawan, A. Purnama, D. Dube, J. Couet, D. Mantovani, Acta. Biomater. 6 (2010) 1852-1860.

[5] P.P. Mueller, S. Arnold, M. Badar, D. Bormann, H. Haferkamp, A. Drynda, A. Meyer-Lindenberg, H. Hauser, M. Peuster, J. Biomed. Mater. Res. A 100 (2012) 2881-2889.

[6] M. Schinhammer, I. Gerber, A.C. Hänzi, P.J. Uggowitzer, Mater. Sci. Eng. C 33 (2013) 782-789.

[7] F. Witte, N. Hort, C. Vogt, S. Cohen, K. U. Kainer, R. Willumeit ,F. Feyerabend, Curr. Opin. Solid. St. M. 12 (2008) $63-72$.

[8] Z. Zhen, X.L Liu, T. Huang, T.F Xi, Y.F Zheng, Mater. Sci. Eng. C 46 (2015) 202-206.

[9] J. Wang, V. Giridharan, V. Shanov, Z.G. Xu, B. Collins, L. White, Y. Jang, J. Sankar, N. Huang, Y. Yun, Biomater. 10 (2014) 5213-5223.

[10] D. Pierson, J. Edick, A. Tauscher, E. Pokorney, P. K. Bowen, J. Gelbaugh, J. Stinson, H. Getty, C.H. Lee, J. Drelich, J. Goldman, J. Biomed. Mater. Res. B 100B (2012) 58-67.

[11] Y.F. Zheng, X.N. Gu, F. Witte, Mater. Sci. Eng. R 77 (2014) 1-34.

[12] K. M. Hambridge, N. F. Krebs, J. Nutr. 137 (2007) 1101-1105.

[13] R. Hansch, R.R. Mendel, Curr. Opin. Plant Biol. 12 (2009) 259-266.

[14] P. Trumbo, A.A. Yates, S. Schlicker, M. Poos, J. Am. Diet. Assoc. 101 (2001) 294-301.

[15] D. Vojte`ch, J. Kubásek, J. Šerák, P. Novák, Acta Biomater. 7 (2011) 3515-3522.

[16] H.F. Li, H.T. Yang, Y.F. Zheng, F.Y. Zhou, K.J. Qiu, X. Wang, Mater. Design 83 (2015) 95-102.

[17] C.Z. Yao, Z.C. Wang, S.L. Tay, T.P. Zhu, W. Gao, J. Alloy. Compd. 602 (2014) 101-107.

[18] P.K. Bowen, J. Drelich, J. Goldman, Adv. Mater. 25 (2013) 2577-2582.

[19] B.P. Murphy, P. Savage, P.E. McHugh, D.F. Quinn, Ann. Biomed. Eng. 31 (2003) 686-691.

[20] P. Savage, B.P. O'Donnell, P.E. McHugh, B.P. Murphy, D.F. Quinn, Ann. Biomed. Eng. 32 (2004) $202-211$.

[21] K. Hanada, K. Matsuzaki, X.S. Huang, Y. Chino, Mater. Sci. Eng. C 33 (2013) 4746-4750.

[22] J. Cheng, B. Liu, Y.H. Wu, Y.F. Zheng, J. Mater. Sci. Technol. 29 (2013) 619-627.

[23] A. Oyane, H.M. Kim, T. Furuya, T. Kokubo, T. Miyazaki, T. Nakamura, J. Biomed. Mater. Res. - Part A 65 (2003) $188-195$.

[24] G. Celano, S. Fichera, L. Fratini, J. Mater. Process. Tech. 113 (2001) 380-685.

[25] J. Luksza, M. Burdek, J. Mater. Process. Tech. 125-126 (2002) 725-730.

[26] R.N. Wright, Wire technology - process engineering and metallurgy, Butterworth-Heinemann, Burlington, 2011, pp. $65-74$.

[27] G. Fang, W.J. Ai, S. Leeflang, J. Duszczyk, J. Zhou, Mater. Sci. Eng. C 33 (2013) 3481-3488.

[28] L.X. Wang, G. Fang, L.Y. Q, S. Leeflang, J. Duszczyk, J. Zhou, Prog. Nat. Sci-Mater. 24 (2014) 500-506

[29] S. Codet, L. Jiang, A.A. Luo, J.J. Jonas, Scripta Mater. 55 (2006) 1055-1058.

[30] J.A. del Valle, F. Carreño, O.A. Ruano, Acta Mater. 54 (2006) 4247-4259.

[31] T. Al-Samman, K.D. Molodov, D.A. Molodov, G. Gottstein, S. Suwas, Acta Mater. 60 (2012) 537-545.

[32] F. Liu, C.X Chen, J.L. Niu, J. Pei, H. Zhang, H. Huang, G.Y. Yuan, Mater. Sci. Eng. C 48 (2015) 400-407.

[33] M.S. Dambatta, S. Izman, D. Kurniawan, S. Farahany, B. Yahaya, H. Hermawan, Mater. Design 85 (2015) $431-437$.

[34] Q. Wu, S.J. Zhu, L.G. Wang, Q. Liu, G.C. Yue, J. Wang, S.K. Guan, J. Mech. Behav. Biomed. 8 (2012) 1-7. 


\section{Figure and table captions}

Table 1 Typical different drawing conditions of $\mathrm{Zn}$ alloy micro-tubes

Table 2 Mechanical properties of $\mathrm{Zn}$ alloy micro-tubes with different drawing conditions

Fig. 1 Schematic diagrams of hollow sinking and mandrel drawing

Fig. $2 \mathrm{Zn}$ alloy tubes: (a) from drilled tubes to micro-tubes, (b) and (c) $3.0 \mathrm{~mm}$ rolled micro-tube, (d) and (e) $2.5 \mathrm{~mm}$ drawn micro-tube

Fig. 3 Dimensional accuracy of the drawn Zn alloy micro-tubes ( $\$ 2.5 \mathrm{~mm} \times 130 \mu \mathrm{m})$

Fig. 4 Microstructure of the Zn alloy tubes: (a) and (b) drilled tubes, (c) and (d) $3.0 \mathrm{~mm}$ rolled micro-tube, (e) and (f) $2.5 \mathrm{~mm}$ drawn micro-tube, (g) and (h) $2.5 \mathrm{~mm}$ drawn tube after annealing

Fig. 5 Morphology of the micro-tubes after immersion test: (a) rolled $\mathrm{Zn}$ alloy, (b) drawn $\mathrm{Zn}$ alloy, (c) drawn AZ31 alloy

Fig. 6 Weight loss percentage of $\mathrm{Zn}$ alloy micro-tubes during immersion test

Fig. $7 \mathrm{Zn}$ alloy stent: (a) after polishing, (b) crimped into $1.3 \mathrm{~mm}$, (c) expanded into $3.5 \mathrm{~mm}$ 
Table list:

Table 1 Typical different drawing conditions of $\mathrm{Zn}$ alloy micro-tubes

\begin{tabular}{lcccc}
\hline No. & Drawing method & $R / P$ & DP & Lubricant \\
\hline 1 & HS/ MD & $25 \%$ & 1 & Oil \\
2 & HS/ MD & $15 \%$ & 1 & Oil \\
3 & HS & $7 \%$ & 3 & Oil \\
4 & HS & $4 \%$ & 5 & Oil \\
5 & HS & $2 \%$ & 10 & Oil \\
6 & HS & $4 \%$ & 5 & MoS $_{2}$ \\
7 & MD & $<15 \%$ & 2 & Oil $^{2}$ \\
\hline
\end{tabular}

Table 2 Mechanical properties of Zn alloy micro-tubes with different drawing conditions

\begin{tabular}{lcccc}
\hline No. & Drawing possibility & UTS (MPa) & YS (MPa) & Elongation (\%) \\
\hline 1 & Brittle failure & - & - & - \\
2 & Surface flaw & - & - & - \\
3 & Feasible & $180-186$ & $151-158$ & $12-18$ \\
4 & Feasible & $211-218$ & $174-186$ & $16-21$ \\
5 & Feasible & $189-197$ & $154-163$ & $7-11$ \\
6 & Feasible & $184-193$ & $122-134$ & $5-8$ \\
7 & Feasible & $223-231$ & $176-187$ & $22-26$ \\
\hline
\end{tabular}


Figure list:

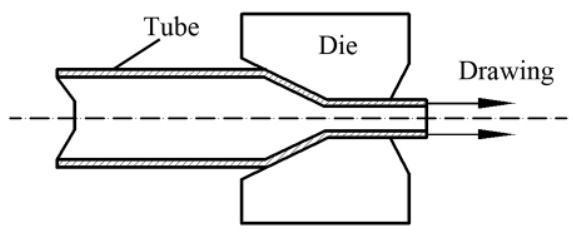

(a) Hollow sinking

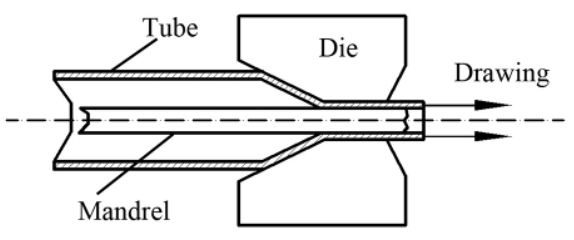

(b) Mandrel drawing

Fig. 1
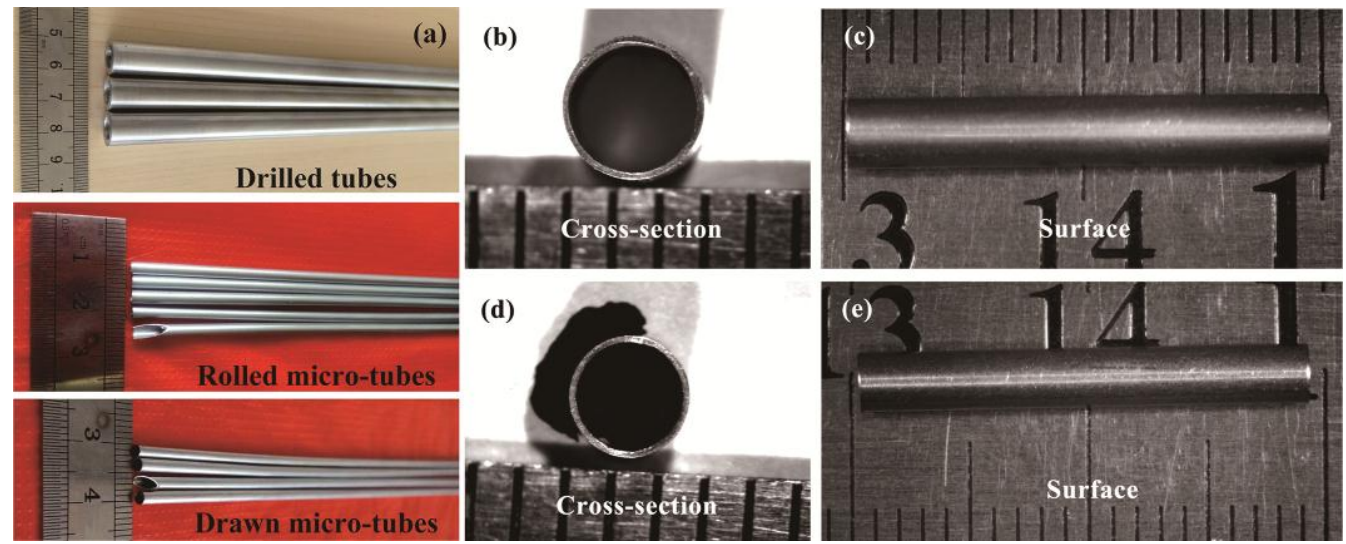

Fig. 2

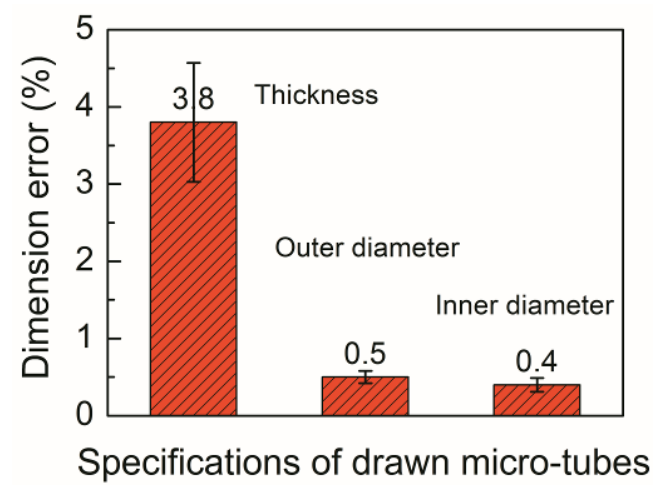

Fig. 3 


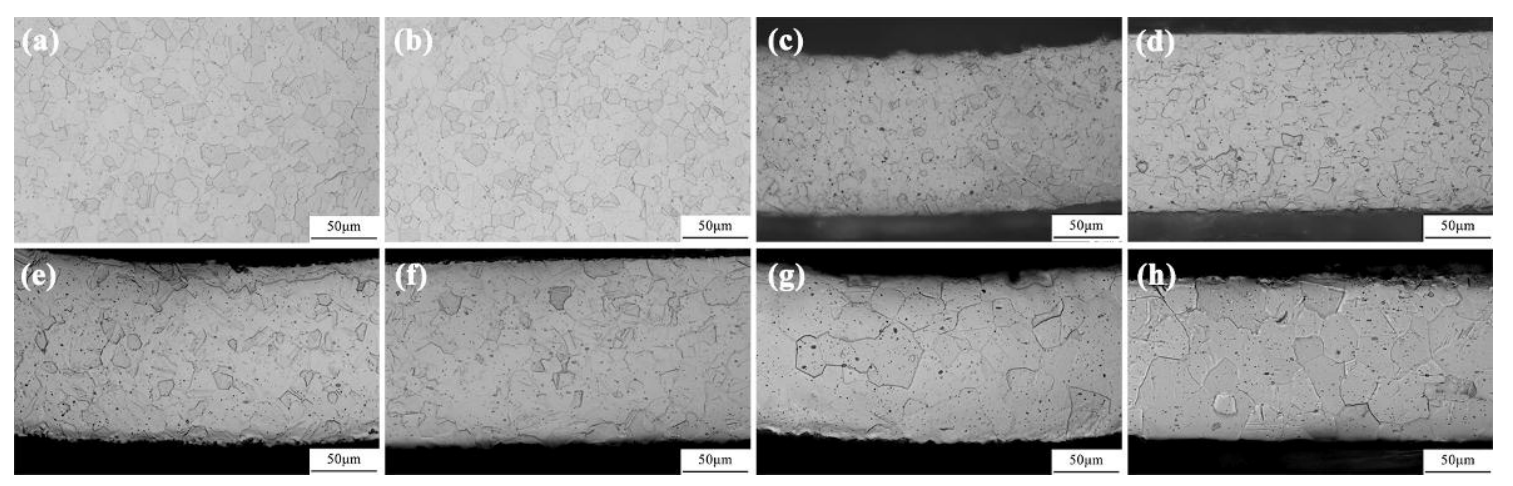

Fig. 4

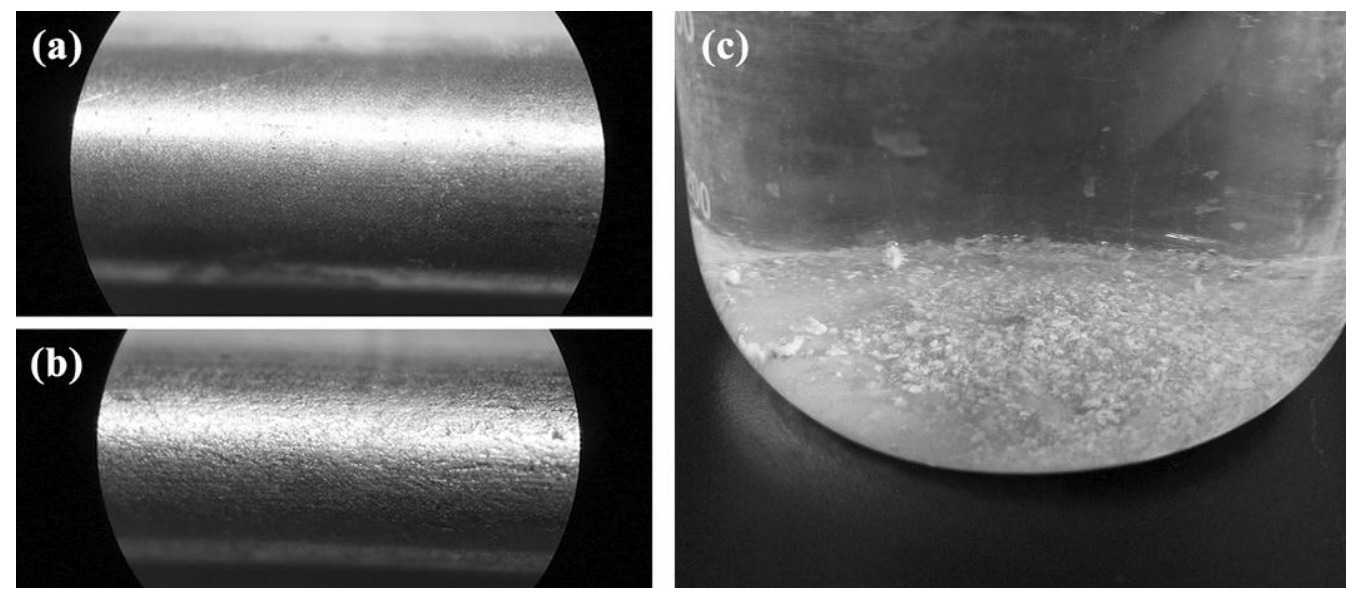

Fig. 5

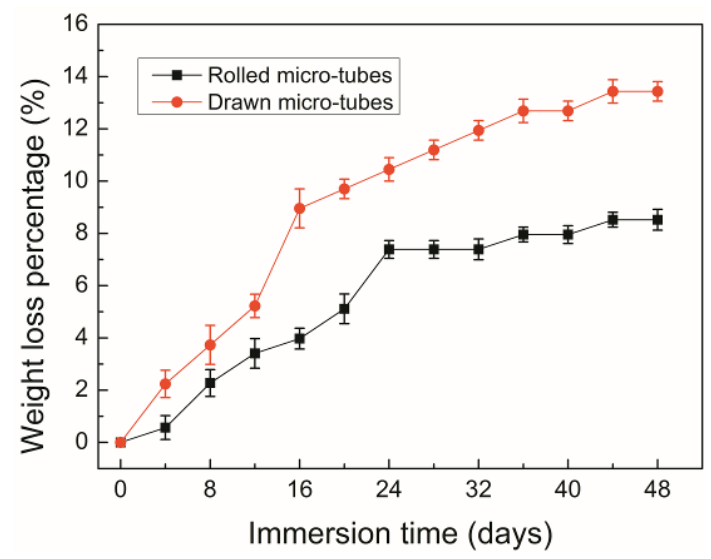

Fig. 6 


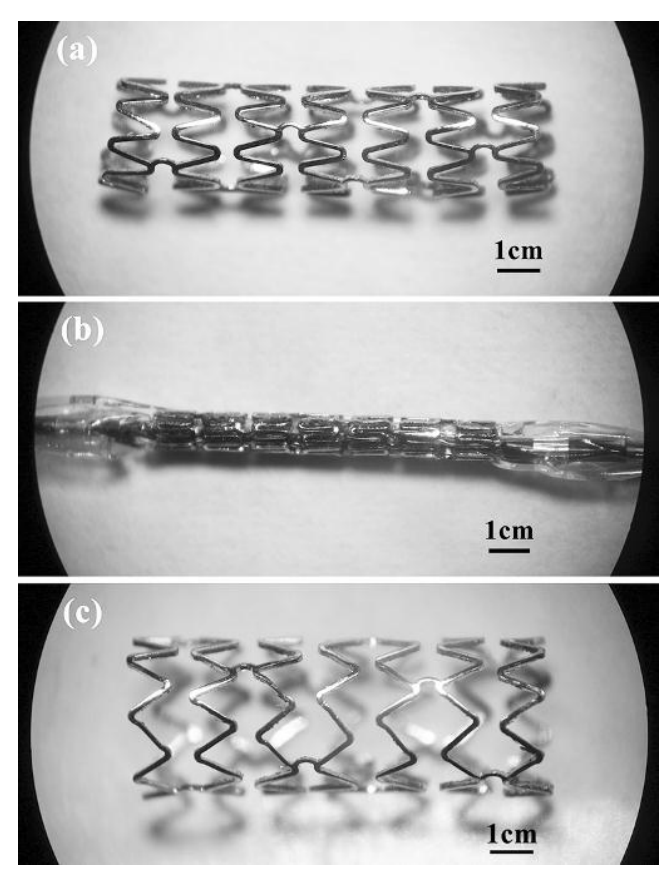

Fig. 7 